\title{
A PROSPECTIVE, RANDOMISED, COMPARATIVE STUDY OF EFFICACY AND SAFETY OF PREGABALIN, DULOXETINE AND AMITRIPTYLINE IN PATIENTS OF PAINFUL DIABETIC NEUROPATHY IN A TERTIARY CARE TEACHING HOSPITAL IN RURAL BENGAL
}

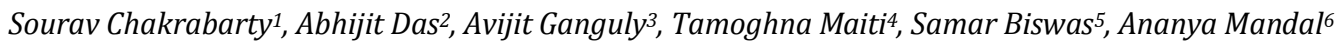 \\ ${ }_{1}^{1}$ Post Graduate Trainee, Department of Pharmacology, Bankura Sammilani Medical College, Bankura, West Bengal. \\ ${ }^{2}$ Associate Professor, Department of Pharmacology, Bankura Sammilani Medical College. \\ ${ }_{3}^{3}$ Post-Doctoral Trainee, Department of Pharmacology, Calcutta School of Tropical Medicine, Kolkata. \\ ${ }^{4}$ Associate Professor, Department of Pharmacology, Bankura Sammilani Medical College. \\ 5 Assistant Professor, Department of Neurology, Bankura Sammilani Medical College. \\ ${ }^{6}$ Associate Professor, Department of Pharmacology, Bankura Sammilani Medical College.
}

\section{ABSTRACT}

Painful Diabetic Polyneuropathy (DPN) is one of the commonest microvascular complications, affecting nearly $26 \%$ of diabetic patients. Amitriptyline, Duloxetine and Pregabalin are all approved internationally for managing neuropathic pain apart from strict glycaemic control.

\section{OBJECTIVES}

To compare efficacy and safety of Pregabalin, Duloxetine and Amitriptyline in reducing neuropathic pain as well as improving quality of sleep among patients of DPN.

\section{METHODOLOGY}

We performed an open label, prospective, randomized, 12 week, observational study, at the Neurology OPD at B. S. Medical College. A total of $93 \mathrm{DM}$ patients with baseline pain score $>4$ in numeric pain rating scale were enrolled and randomized to receive Pregabalin ( $n=31)$, Duloxetine $(n=31)$ and Amitriptyline $(n=31)$. Severity of neuropathic pain as assessed by NPSI score was recorded at baseline after 4 weeks and 12 weeks interval along with measurement of glycaemic control. We also measured improvement in sleep quality using PSQI score at all visits. Safety assessment was done by comparing treatment emergent adverse effects and by comparing laboratory parameters.

\section{RESULT}

Final assessment was done in 87 patients excluding 6 dropouts. Status of glycaemic control among all three groups was not significantly different. A significant decrease in mean pain score was seen in all three groups across time ( $<<0.05)$, but no significant difference was noted between the groups. The decrease in pain severity occurred more slowly during first 4 weeks with Amitriptyline than other two drugs. Sleep quality improved in all three groups in the first 4 weeks significantly, but no further significant improvement happened at 12 weeks in any groups. ADRs were mostly mild, occurring in $24.1 \%$ of cases, with highest incidence in patients receiving Amitriptyline.

\section{CONCLUSION}

All these three drugs showed similar efficacy in reducing pain in diabetic polyneuropathy as well as improving the sleep quality. Amitriptyline, relatively inexpensive, may be preferred over the other two in this rural financially disadvantaged population. A large, blinded, multi-centric trial is being planned to find out superiority in safety or efficacy of these drugs.

\section{KEYWORDS}

Diabetes Mellitus, Neuropathic Pain, Pregabalin, Amitriptyline, Randomization, Duloxetine.

HOW TO CITE THIS ARTICLE: Chakrabarty S, Das A, Ganguly A, et al. A prospective, randomised, comparative study of efficacy and safety of pregabalin, duloxetine and amitriptyline in patients of painful diabetic neuropathy in a tertiary care teaching hos pital in rural Bengal. J. Evolution Med. Dent. Sci. 2016;5(35):2025-2029, DOI: 10.14260/jemds/2016/476

\section{INTRODUCTION}

Diabetes mellitus (Both Type I and II), on long term, frequently leads to a number of vascular and non-vascular complications. Neuropathies are the commonest microvascular complication affecting about $50 \%$ of the DM patients. ${ }^{1}$ It results from progressive loss of nerve fibres involving both somatic and autonomic nervous system.

Financial or Other, Competing Interest: None.

Submission 17-03-2016, Peer Review 13-04-2016,

Acceptance 18-04-2016, Published 02-05-2016.

Corresponding Author:

Dr. Avijit Ganguly,

B G 116, Rabindrapally,

Krishnapur, P. O. Prafullakanan,

Kolkata-700101.

E-mail: avijitdec81@gmail.com

DOI: $10.14260 /$ jemds/2016/476
The commonest is length dependent sensorimotor polyneuropathy, manifesting as either loss of sensation or excessive feeling of pain. ${ }^{2}$ Diabetic Polyneuropathy (DPN) can be clinically defined as "the presence of symptoms and/or signs of peripheral nerve dysfunction in people with diabetes after exclusion of other causes." 3 Pain in DPN is due to dysfunction arising from the somatosensory system. $426 \%$ of DM patients suffer from painful DPN with symptoms as spontaneous tingling/burning/shooting type of sensation. ${ }^{5}$ It is also complicated with allodynia and/or hyperalgesia. These patients suffer from disturbed sleep, anxiety and/or depression and poor quality of life. ${ }^{6}$ As DPN is a diagnosis by exclusion, so one has to rule out other possible causes of peripheral neuropathy (Hypothyroidism/Vit B12 deficiency/alcoholism, etc.) and perform detail clinical and electro-physiological assessment to establish diagnosis of PDPN. Management of painful DPN is based on two pillars- 
first strict glycaemic control and secondly reduction of pain by drugs. But sole glycaemic control is not sufficient in DPN, as found in a study done by Sorensen et al. ${ }^{7}$ Moreover neuropathy can develop even in pre-diabetic stage.

A number of agents like $\alpha$ lipoic acid/C-peptide/protein kinase $C$ - $\beta$ inhibitors, etc. have been tried in clinical trials as disease modifying agents of DPN, but none proved to be effective yet. ${ }^{2}$ Till now, we have only the drugs that will provide symptomatic relief of neuropathic pain without any role in arresting disease progression. Available medications include

Anticonvulsants (Pregabalin/Gabapentin/Oxcarbazepine/valproate), Antidepressants (Amitriptyline, Duloxetine, venlafaxine, Imipramine), opioids (Tramadol/oxycodone), capsaicin, lidocaine, etc. In spite of many available agents, pain control is very difficult to achieve in patients with DPN. Only two agents approved by U. S. food and Drug Administration for neuropathic pain are Pregabalin and duloxetine. ${ }^{9}$ Amitriptyline, a widely used tricyclic antidepressant, is also regarded as first line agents for neuropathic pain by American Diabetes Association. 10

Published International guidelines including the European Federation of Neurological Sciences (EFNS) and International Association for the study of Pain (IASP) showed level A evidence for use of Tricyclic Antidepressants in PDPN.11,12 As per our knowledge, no study was performed regarding head to head comparison of safety, efficacy and tolerability of these three first line drugs among Indian patients with DPN. Hence, we decide to perform a comparative study of safety and efficacy of Pregabalin, Duloxetine and Amitriptyline in patients with DPN as well as their role in improving their quality of sleep in the Neurology OPD at Bankura Sammilani Medical College.

\section{MATERIALS AND METHODS}

\section{Study Objectives}

Primary objective of our study was to find out the drug with maximum efficacy in reducing neuropathic pain, as measured by mean Neuropathic Pain Symptom Inventory (NPSI) score in a treatment group. ${ }^{13}$ We also had two Secondary objectives, first to find out the drug which causes maximum improvement of quality of sleep as measured by the Pittsburgh Sleep Quality Index (PSQI) score and secondly to compare incidence of treatment emergent adverse event in each treatment groups. ${ }^{14}$ It was an Institution based, unicentric, randomised, openlabel, parallel group, 12-week comparative study with three treatment arms done at Neurology Outpatient Department in the Bankura Sammilani Medical College for a duration of 6 months starting from $1^{\text {st }}$ June to 30 ${ }^{\text {th }}$ November 2015.

\section{Study Population}

Patients of Diabetes mellitus attending Neurology OPD at BSMCH with the following criteria.

\section{Inclusion Criteria}

1. Diagnosed by consultant physician as having painful diabetic neuropathy.

2. Scoring $\geq 4$ at Michigan Neuropathy Symptom Inventory (MNSI) scores. ${ }^{15}$
3. Scoring $\geq 4$ at baseline Numeric pain rating scale.

4. Age 18-75 years.

\section{Exclusion Criteria}

1. Those with diagnosed neurological diseases other than DPN.

2. Those with serum Creatinine level $\geq 1 \mathrm{mg} \%$.

3. SGPT level $>3$ fold than normal level.

4. Ischaemic heart disease/Cardiac conduction defect/Congestive cardiac failure.

5. H/O urinary retention.

6. Pregnant and lactating women.

A sample size of 90 was determined assuming $20 \%$ dropouts using predetermined value of level of significance as 0.05 , power of the study as $80 \%$, expected difference in decreasing NPSI score at least 20 from baseline and standard deviation of NPSI being 24.8 as determined by a pilot study. We decided to allocate 30 patients to each groups. Randomization was done using computer generated random number table and treatment allocation was done according to their numbers. This study was done following the principles of the Declaration of Helsinki for study on human subjects. Prior approval was taken from Institutional Ethics Committee and written informed consent was taken from patients or their legal representatives.

\section{Collection of Data}

After being diagnosed by consultant physician as having PDPN, the patients were explained in detail regarding study technique and written consent were obtained. Willing subjects were enrolled according to the inclusion and exclusion criteria. Baseline assessment of demographic details, BMI, Blood sugar level, HbA1C, lipid profile, liver and renal function and NPSI and PSQI score was done. Patients were prescribed study medications according to their allocation on the basis of randomization. Patients from each group received either 150 mg Pregabalin, $25 \mathrm{mg}$ of Amitriptyline or $30 \mathrm{mg}$ Duloxetine. They were followed up on two occasions after 4 weeks and 12 weeks from date of enrolment. We assessed NPSI and PSQI score, BMI and fasting blood sugar level only after 4 weeks. At the end of 12 weeks, all baseline investigations and clinical assessments were repeated. Safety of the drugs was assessed by the incidence of treatment emergent adverse events as they reported. Details of ADRs, their appearance, temporal relationship with the drugs, causality and severity were recorded.

\section{Statistical Analysis}

All data were entered into SPSS 22 software and further analysed. All analyses were two sided. A p value less than 0.05 was set to be significant. We used intent-to-treat principle and Last Observation Carried Forward (LOCF) method for analysis of the variables. Descriptive statistics were expressed as percentages, mean \pm SD for continuous parametric variables. Repeated measures Analysis of Variance (ANOVA) was performed to find any significant difference of NPSI score and PSQI score across time in all the three groups and followed by post-hoc Bonferroni-corrected pair-wise t-test. 
The Flow Chart of Data Collection

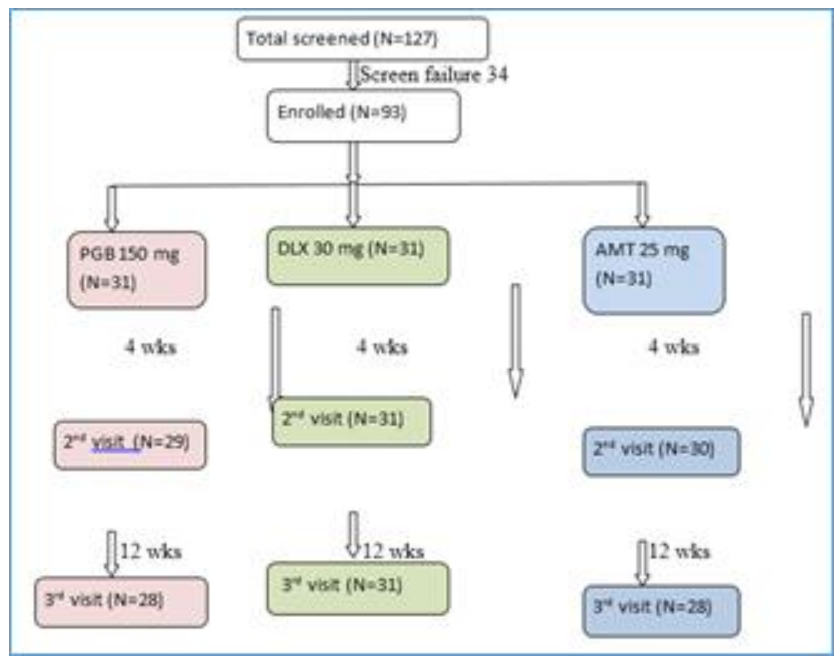

The Demographic Details and Baseline Parameters are given in Table 1.

\begin{tabular}{|c|c|c|c|c|}
\hline $\begin{array}{c}\text { Characteri- } \\
\text { stic }\end{array}$ & $\begin{array}{c}\text { Pregabalin } \\
\quad(N=28)\end{array}$ & $\begin{array}{c}\text { Duloxetine } \\
(\mathrm{N}=31)\end{array}$ & $\begin{array}{c}\text { Ami- } \\
\text { triptyline } \\
(\mathrm{N}=28)\end{array}$ & $\begin{array}{c}\mathbf{P} \\
\text { value }\end{array}$ \\
\hline Age & $\begin{array}{c}53.37 \\
(10.045) \\
\end{array}$ & $\begin{array}{c}56.752 \\
(10.853) \\
\end{array}$ & $\begin{array}{c}53.157 \\
(10.714) \\
\end{array}$ & 0.917 \\
\hline BMI & $\begin{array}{c}26.95 \\
(4.835)\end{array}$ & $\begin{array}{l}27.473 \\
(2.931)\end{array}$ & $\begin{array}{l}25.421 \\
(4.501)\end{array}$ & 0.297 \\
\hline SBP & $\begin{array}{c}149.16 \\
(18.261) \\
\end{array}$ & $\begin{array}{l}142.315 \\
(20.723) \\
\end{array}$ & $\begin{array}{l}142.842 \\
(18.163)\end{array}$ & 0.474 \\
\hline DBP & $\begin{array}{c}78.00 \\
(11.372) \\
\end{array}$ & $\begin{array}{c}82.526 \\
(11.330) \\
\end{array}$ & $\begin{array}{l}83.052 \\
(9.002)\end{array}$ & 0.281 \\
\hline $\begin{array}{c}\text { Total } \\
\text { Cholesterol }\end{array}$ & $\begin{array}{c}186.58 \\
(16.938)\end{array}$ & $\begin{array}{c}173.526 \\
(8.140)\end{array}$ & $\begin{array}{l}174.842 \\
(10.420)\end{array}$ & 0.003 \\
\hline HBA1C & $\begin{array}{c}8.6 \\
(1.2)\end{array}$ & $\begin{array}{c}8.1 \\
(1.1)\end{array}$ & $\begin{array}{c}7.8 \\
(1.2)\end{array}$ & 0.142 \\
\hline FBS & $\begin{array}{c}159.41 \\
(43.3)\end{array}$ & $\begin{array}{c}171 \\
(52.6)\end{array}$ & $\begin{array}{c}166.72 \\
(49.5)\end{array}$ & 0.415 \\
\hline $\begin{array}{c}\text { Serum } \\
\text { Creatinine }\end{array}$ & $\begin{array}{l}0.79 \\
(.15)\end{array}$ & $\begin{array}{l}0.81 \\
(.13)\end{array}$ & $\begin{array}{l}0.87 \\
(11)\end{array}$ & 0.150 \\
\hline $\begin{array}{l}\text { Duration of } \\
\text { DM in years }\end{array}$ & $\begin{array}{l}8.12 \\
(3.8)\end{array}$ & $\begin{array}{l}7.93 \\
(3.4)\end{array}$ & $\begin{array}{l}8.31 \\
(3.2)\end{array}$ & 0.537 \\
\hline $\begin{array}{c}\text { Duration of } \\
\text { DPN } \\
\text { in months }\end{array}$ & $\begin{array}{l}7.59 \\
(1.3)\end{array}$ & $\begin{array}{l}8.41 \\
(1.6)\end{array}$ & $\begin{array}{l}7.70 \\
(2.0)\end{array}$ & 0.877 \\
\hline MNSI score & $\begin{array}{c}8.71 \\
(1.61)\end{array}$ & $\begin{array}{c}9.11 \\
(1.17)\end{array}$ & $\begin{array}{c}8.93 \\
(1.23)\end{array}$ & 0.231 \\
\hline NPSI score & $\begin{array}{c}67.94 \\
(20.07)\end{array}$ & $\begin{array}{l}68.157 \\
(16.39)\end{array}$ & $\begin{array}{c}63.15 \\
(20.97)\end{array}$ & 0.666 \\
\hline PSQI score & $\begin{array}{c}5.52 \\
(5.52) \\
\end{array}$ & $\begin{array}{c}6.36 \\
(6.36) \\
\end{array}$ & $\begin{array}{c}6.94 \\
(5.33) \\
\end{array}$ & 0.742 \\
\hline \multicolumn{5}{|c|}{ Table 1} \\
\hline
\end{tabular}

So it is evident from the table that the baseline parameters were not significantly different in these three treatment groups, except the serum cholesterol level where the Pregabalin group patients showed a significantly higher level of serum cholesterol than the other two groups. Regarding control of hyperglycaemia, there was no significant difference $(\mathrm{p}>0.05)$ in changes in mean HBA1C level or fasting blood glucose level over 12 weeks from baseline value.

\section{Mean NPSI Score}

All the three treatment groups showed a significant decrease in NPSI score from baseline across time $(\mathrm{p}<0.001)$ as shown in Table 2 and Figure 1 with no significant difference between the groups $(\mathrm{p}=0.989)$. But the test for within subjects contrast (Table 3) showed that there was significant time - drug interaction in baseline vs. first visit NPSI values $(p=0.029)$, but no such interaction was noted in subsequent visits. While looking at the profile plot of estimated marginal means of NPSI score (Figure 2) for different drugs, we interpreted that amitriptyline group patients showed slower reduction of NPSI values than during first 4 weeks than Pregabalin and amitriptyline. Later, that was confirmed by paired ' $t$ ' test taking two drugs in pair (PGB vs. AMT, DLX vs. AMT, PGB vs. DLX) and also by post-hoc test.

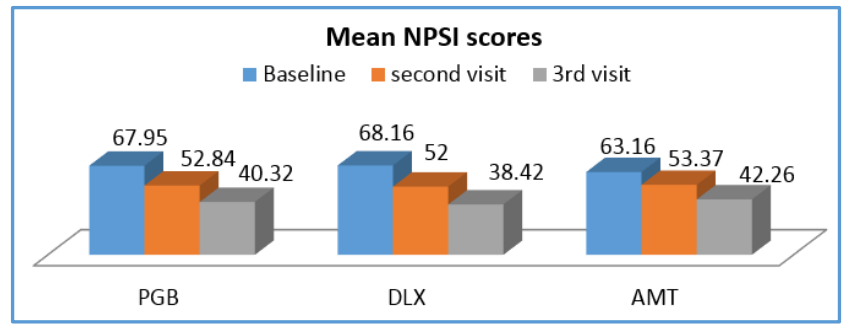

Fig. 1: Descriptive Statistics (NPSI Score)

\begin{tabular}{|c|c|}
\hline Effect & Significance \\
\hline Visit & $<0.001$ \\
\hline Visit* DRUG $^{*}$ Table 2: Within Subjects' Effect (NPSI Score) \\
\hline
\end{tabular}

\begin{tabular}{|c|c|c|}
\hline Source & Visit & Significance \\
\hline Visit & Baseline vs. $2^{\text {nd }}$ visit & $<0.001$ \\
\hline & $2^{\text {nd }}$ visit vs. $3^{\text {rd }}$ visit & $<0.001$ \\
\hline Visit* DRUG & Baseline vs. $2^{\text {nd }}$ visit & 0.029 \\
\hline & $2^{\text {nd }}$ visit vs. $3^{\text {rd }}$ visit & 0.564 \\
\hline
\end{tabular}

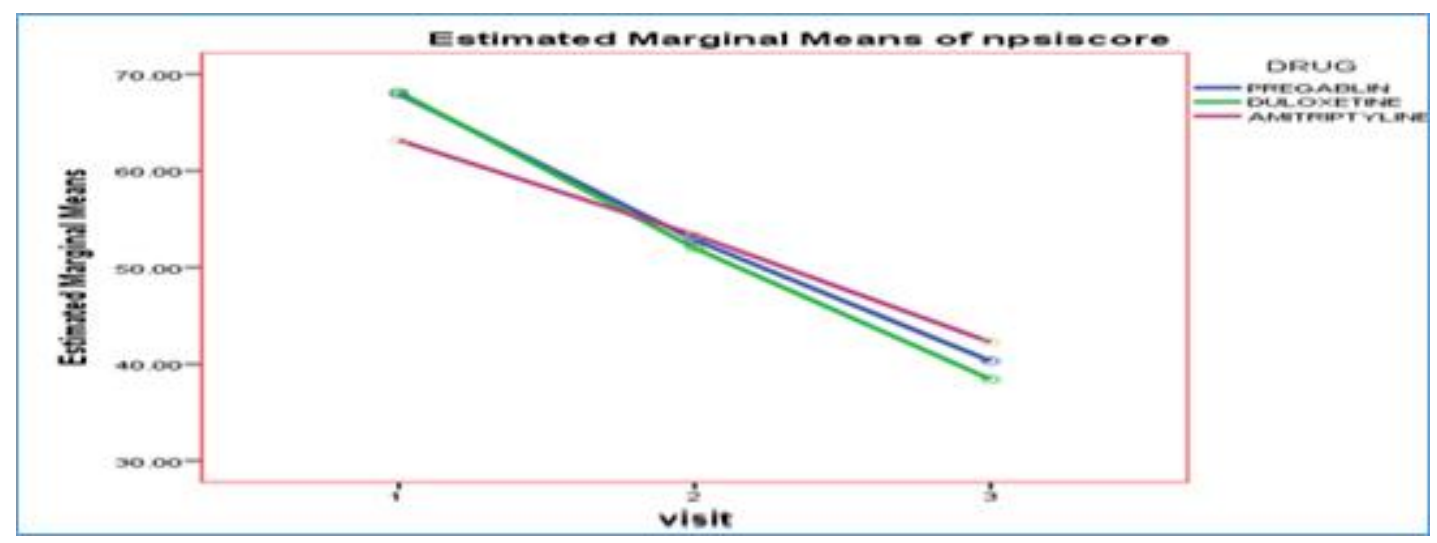

Fig. 2: Profile Plot showing Estimated Marginal Means of NPSI Score 


\section{Mean PSQI Score}

Again, we found that all three treatment groups showed a significant decrease in PSQI score across time $(p<0.001)$ without observing any significant time drug interaction $(\mathrm{p}=0.107)$ or any between subject effect $(\mathrm{p}=0.599)$ as shown in Table 4 and Figure 3. But in tests of within-subjects contrast (Table 5), we found that the reduction in PSQI score was significant in first 4 weeks in all three groups $(\mathrm{p}<0.001)$, but during the subsequent visits there was no significant reduction of PSQI score( $\mathrm{p}=0.287)$ in any group.

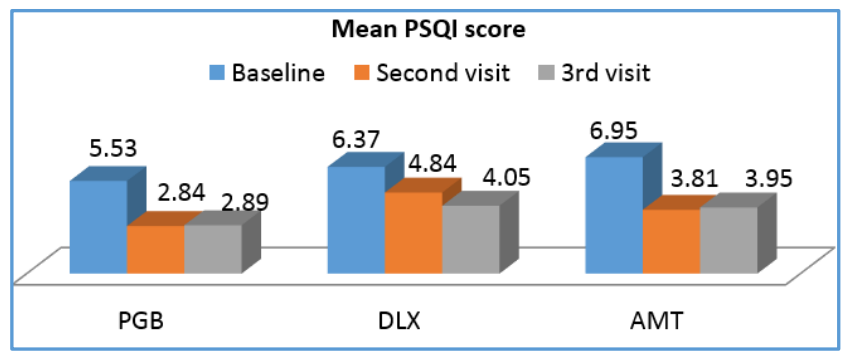

Fig. 3: Descriptive Statistics of PSQI Score

\begin{tabular}{|c|c|}
\hline Effect & Significance \\
\hline Visit & $<0.001$ \\
\hline Visit* DRUG & 0.107 \\
\hline \multicolumn{2}{|c|}{ Table 4: Within Subjects Effect of PSQI Score } \\
\hline
\end{tabular}

\begin{tabular}{|c|c|c|}
\hline Source & Visit & Significance \\
\hline Visit & Baseline vs. 2 $^{\text {nd }}$ visit & $<0.001$ \\
\hline & $2^{\text {nd }}$ visit vs. 3 ${ }^{\text {rd }}$ visit & 0.287 \\
\hline Visit* DRUG & ${\text { Baseline vs. } 2^{\text {nd }} \text { visit }}^{\text {ng }}$ & 0.123 \\
\hline & $2^{\text {nd }}$ visit vs. 3 ${ }^{\text {rd }}$ visit & 0.121 \\
\hline \multicolumn{2}{|c|}{ Table 5: Tests of Within Subjects Contrast (PSQI Score) } \\
\hline
\end{tabular}

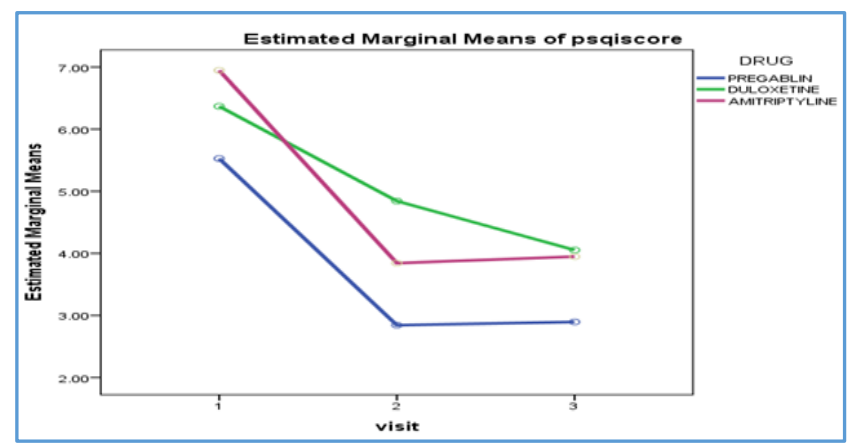

Fig. 4: Profile Plot showing Estimated Marginal Means of PSQI Score

\section{Safety and Tolerability}

We encountered a total of 70 ADRs in 21 patients. Two patients in PGB group left the study for excessive vertigo and postural hypotension. There were 3.3 ADRs per case; $48 \%$ of ADRs occurred in patients receiving Amitriptyline while Duloxetine and Pregabalin group patients suffered from 23\% and 29\% of total ADRs respectively; $97 \%$ of the ADRs were mild and did not require any discontinuation of therapy or any antidotes. Regarding biochemical changes, i.e. Lipid profile, kidney function, LFT all three groups were comparable.

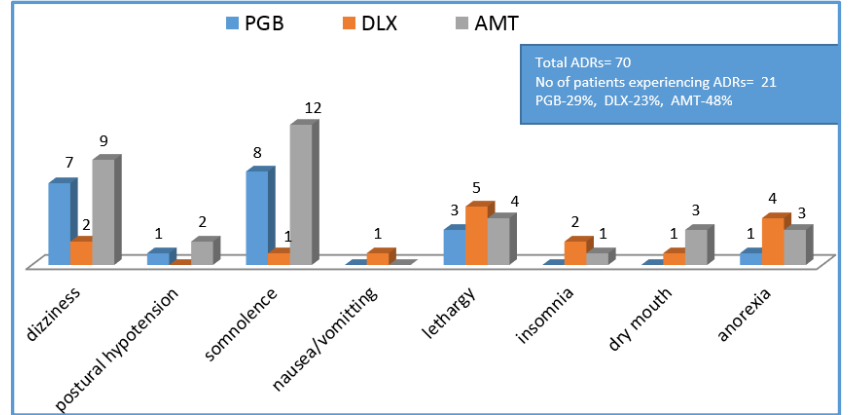

Fig. 5: Showing the Incidence of Different ADRs in Different Groups

\section{DISCUSSION}

In this 12 weeks followup study, we wanted to find the drug with maximum efficacy and better tolerability in patients of DPN as well as to compare the level of improvement of their sleep quality. We found in our study that Pregabalin, duloxetine and amitriptyline all three are equally effective in subjective pain control without having any significant difference. Amitriptyline group patients showed relatively slower improvement of pain during first 4 weeks of treatment than the other two drugs. However, this difference was not seen on further followup. Regarding improvement of sleep quality, we found that all three drugs caused improvement of sleep quality during first 4 weeks, but that effect was not statistically significant during further followup.

Hence, the improvement of sleep quality was due to both improved pain sensation as well as sedative action of the drugs. Though the pain decreased also after 4 weeks, but the overall sleep quality did not improve as the sedative action weaned off later on. Regarding safety and tolerability, all three drugs were found to be tolerable except in two patients receiving Pregabalin. ADRs were common, but mostly mild in nature. Highest percentage of ADRs occurred in Amitriptyline group. Commonest ADR was somnolence followed by dizziness. Our study results were comparable to the previous studies as mentioned below.

Padmini et al (2011). 16 found that there was a significant reduction in pain score among Pregabalin, gabapentin and duloxetine where the initial phase of treatment shows faster rate of improvement with Pregabalin than the other two. There was also improvement of sleep interference score with all three drugs, though Pregabalin groups showed better results than other two. Regarding patient global impression of change score Pregabalin was found to be more preferred by the patients than other. They allowed dose titration according to response of the patients, but in our study we have kept the doses fixed at all level of the study.

Kaur et al (2011) in their study. ${ }^{17}$ found that amitriptyline and duloxetine both demonstrated comparable safety and efficacy profile in DPN patients. Majority of the patients showed $>50 \%$ improvement of pain score. There was resurgence of pain score during the wash out and run out period indicating inability of these drugs to affect the basic pathophysiology of DPN. They also found significant improvement of sleep quality in these patients. ADRs were comparable in both groups.

Achar et al (2010).18 made a randomized comparative study of Pregabalin and amitriptyline as immunotherapy and also in combination, in post-herpetic neuralgia patients where 
they found significant satisfactory improvement ( $>75 \%)$ in pain perception only after 8 weeks of treatment in combined group than the monotherapy groups. Though the subjective pain sensation is comparable in Diabetic Polyneuropathy and Post-Herpetic Neuralgia (PHN), but the rate of improvement is slower in PHN than DPN with these medications.

Tanenberg et al (2011) in their study.19 found that duloxetine in DPNP with inadequate response to Gabapentin is non-inferior to Pregabalin. Rather it could provide better pain reduction, particularly in those who were not taking any antidepressants. No significant differences in TEAE were noted among duloxetine and Pregabalin groups.

A meta-analysis done by Quilici et al (2009). ${ }^{9}$ showed no significant difference in pain score between PGB and DLX, but PGB was more favourable according to Patient Global Impression of Change (PGIC) than DLX.

\section{CONCLUSION}

Our study had some limitations. First, it was an open label study and no blinding was done. Secondly, we did not include a placebo arm due to ethical issues. Thirdly, no dose escalation was permitted at any level. Fourth, status of glycaemic control was a big confounding factor in this study. Improvement of pain quality is also contributed by improved glycaemic status of the patients.

But to conclude, our study showed that these three drugs were equally effective in improving pain as well as improving sleep quality. Amitriptyline, being cheaper than the other two can be preferred especially in economically challenged patients. A long duration, double blinded randomized controlled trial is being planned to find any superiority of either of these drugs.

\section{REFERENCES}

1. Veves A, Backonja M, Malik RA. Painful diabetic neuropathy: epidemiology, natural history, early diagnosis and treatment options. Pain Med 2008;9(6):660-74.

2. Tesfaye S, Boulton AJM, Dyck PJ, et al. Diabetic neuropathies: update on definitions, diagnostic criteria, estimation of severity, and treatments. Diabetes Care 2010;33(10):2285-93.

3. Boulton AJM, Gries FA, Jervell JA. Guidelines for the diagnosis and outpatient management diabetic peripheral neuropathy. Diabet Med 1998;15(6):508-14.

4. Treede RD, Jensen TS, Campbell JN, et al. Neuropathic pain: redefinition and a grading system for clinical and research purposes. Neurology 2008;70(18):1630-5.

5. Davies M, Brophy S, Williams R, et al. The prevalence, severity, and impact of painful diabetic peripheral neuropathy in type 2 diabetes. Diabetes Care 2006;29(7):1518-22.

6. Galer BS, Gianas A, Jensen MP. Painful diabetic polyneuropathy: epidemiology, pain description, and quality of life. Diabetes Res Clin Pract 2000;47(2):123-8.
7. Sorensen L, Molyneaux L, Yue DK. Insensate versus painful diabetic neuropathy: the effects of height, gender, ethnicity and glycaemic control. Diabetes Res Clin Pract 2002;57(1):45-51.

8. Reljanovic M, Reichel G, Rett K, et al. Treatment of symptomatic diabetic polyneuropathy with the antioxidant thiocticacid (lipoicacid): a two year multicenter randomized double-blind placebo controlled trial (ALADIN II). Free Radic Res 1999;31(3):171-9.

9. Quilici S, Chancellor J, Löthgren M, et al. Meta analysis of duloxetine vs. pregabalin and gabapentin in the treatment of diabetic peripheral neuropathic pain. BMC Neurol 2009;9:6.

10. American Diabetes Association. Standards of medical care in diabetes-2009. Diabetes Care 2009;32(1):S13S61.

11. Attal N, Cruccu G, Baron R. EFNS guidelines on the pharmacological treatment of neuropathic pain: 2010 revision. Eur J Neurol 2010;17(9):1113-e88.

12. Finnerup NB, Sindrup SH, Jensen TS. The evidence for pharmacological treatment of neuropathic pain. Pain 2010;150(3):573-81.

13. Didier Bouhassira, Nadine Attal, Jacques Fermanian, et al. Development and validation of the neuropathic pain symptom inventory. Pain 2004;108(3):248-57.

14. Buysse DJ, Reynolds III CF, Monk TH, et al. The pittsburgh sleep quality index: a new instrument for psychiatric practice and research. Journal of Psychiatric Research 1989;28(2):193-213.

15. Moghtaderi A, Bakhshipour A, Rashidi H. Validation of michigan neuropathy screening instrument for diabetic peripheral neuropathy. Clinical Neurology and Neurosurgery 2006;108(5):477-81.

16. Devi P, Madhu K, Ganapathy B, et al. Evaluation of efficacy and safety of gabapentin, duloxetine, and pregabalin in patients with painful diabetic peripheral neuropathy. Indian J Pharmacol 2012;44(1):51-6.

17. Kaur H, Hota D, Bhansali A, et al. A Comaparative evaluation of amitriptyline and duloxetine in painful diabetic neuropathy: a randomized, double-blind, crossover clinical trial. Diabetes Care 2011;34(4):818-22.

18. Achar A, Chatterjee G, Ray TG, et al. Comparative study of clinical efficacy with amitriptyline, pregabalin, and amitriptyline plus pregabalin combination in postherpetic neuralgia. Indian J Dermatol Venereol Leprol 2010;76(1):63-5.

19. Tanenberg RJ, Irving GA, Richard CR, et al. Duloxetine, pregabalin, and duloxetine plus gabapentin for diabetic peripheral neuropathic pain management in patients with inadequate pain response to gabapentin: an openlabel, randomized, noninferiority comparison. Mayo Clin Proc 2011;86(7):615-26. doi: 10.4065/mcp. 2010.0681 www.mayoclinicproceedings.com 